\title{
Diagnóstico de sustentabilidade ambiental de uma unidade produtiva na Vila de São Raimundo no município de Castanhal/PA
}

Os problemas ambientais contribuem para o aumento de processos gradativos no solo. 0 manejo incorreto do solo destrói a sua estrutura e por consequência afeta diretamente a capacidade de produção. O objetivo deste trabalho foi adequar sustentavelmente uma pequena propriedade rural no município de Castanha em aspectos socioeconômicos de comercialização de produtos agroflorestais para servir de modelo de preservação e conservação do meio ambiente. As pesquisas realizadas durante este trabalho, contribuíram para a tomada de decisão na recuperação das áreas da propriedade, que apresentavam irregularidades auxiliando na elaboração do projeto de recuperação ambiental. Dessa forma, buscando o equilíbrio entre o cumprimento da legislação ambiental brasileira e a obtenção do resultados positivos para a questão da produção agrícola, associada à conservação do meio ambiente. Com o passar dos anos a recuperação da floresta é considerada satisfatória e as práticas utilizadas pela família fomentam sua qualidade de vida.

Palavras-chave: Adaptação Sustentável; Equilíbrio; Conservação Ambiental.

\section{Diagnosis of environmental sustainability of a productive unit in the Village of São Raimundo in the municipality of Castanhal/PA}

\begin{abstract}
Environmental problems contribute to the increase of gradual processes in the soil. Incorrect soil management destroys its structure and consequently directly affects production capacity. The objective of this work was to sustainably adapt a small rural property in the municipality of Castanhal, in the socioeconomic aspects of marketing agroforestry products to serve the model of conservation and conservation of the environment. As research carried out during this work, they contributed to the decision to recover areas of the property, which showed irregularities in the execution of the environmental recovery project. Thus, seeking balance between compliance with Brazilian environmental legislation and positive results for agricultural production issues, associated with environmental conservation. Over the years, the recovery of the forest is considered satisfactory and the practices used by the family foster their quality of life.
\end{abstract}

Keywords: Sustainable adapt; Balance; Environmental Conservation.

Topic: Conservação da Biodiversidade

Reviewed anonymously in the process of blind peer.
Received: 02/05/2020

Approved: $30 / 06 / 2020$
Deivid Natan Marciel Gabriel do Nascimento (iD

Instituto Federal do Pará, Brasil

http://lattes.cnpq.br/8484510997744916

http://orcid.org/0000-0003-0581-0873

dhcnatan@gmail.com

José Carlos Virgínio dos Santos Junior

Instituto Federal do Pará, Brasil

http://lattes.cnpq.br/5787862458443122

http://orcid.org/0000-0002-9696-9080

jcvirginio@gmail.com

Klewton Adriano Oliveira Pinheiro (it

Instituto Federal do Pará, Brasil

http://lattes.cnpq.br/8139678842009696

http://orcid.org/0000-0003-2696-4249

klewton.pinheiro@gmail.com
Francimary da Silva Carneiro

Universidade Federal Rural da Amazônia, Brasil

http://lattes.cnpq.br/8657235544233319

http://orcid.org/0000-0002-1693-8779

francimarycarneiro@gmail.com
Referencing this:

NASCIMENTO, D. N. M. G.; SANTOS JUNIOR, J. C. V.; PINHEIRO, K. A. O.; CANEIRO, F. S.. Diagnóstico de sustentabilidade ambiental de uma unidade produtiva na Vila de São Raimundo no município de Castanhal/PA. Nature and Conservation, v.13, n.3, p.7-23, 2020. DOI: http://doi.org/10.6008/CBPC2318-2881.2020.003.0002 


\section{INTRODUÇÃO}

Com a chegada do processo de urbanização da Amazônia, com o governo federal oferecendo lotes de terra para que as famílias viessem morar na região, promovendo a criação dos primeiros municípios e o povoamento da região. Após esse processo inicial surgiram nesse meio as indústrias, subsidiando o crescimento do comercio local, juntamente com a busca por novas áreas agrícolas para a obtenção da produção de alimentos e moradias (ALVES, 2012).

A partir do período que a população mundial alcança uma expansão, a necessidade por alimentos, espaço e de condições para sobrevivência fica cada vez maior, fazendo com que as ações antrópicas ao ambiente sejam crescentes. A história do uso do solo mostra que, a alteração no ambiente nem sempre dá lugar a um novo sistema ecológico e sustentável, seja de lavouras ou de pastagens. Com isso, solos utilizados intensamente, e de forma inadequada, são levados à degradação (ALVES, 2001).

A atividade de agricultura de subsistência e pecuária vem sofrendo com a degradação dos ecossistemas ao longo das épocas, dessa forma, vários problemas ambientais vêm se instituindo, dentre eles o aquecimento global. Perante esta situação se torna cada vez mais necessária a restauração de áreas degradadas para diminuir os efeitos negativos da destruição dos ambientes naturais (KAGEYAMA et al., 2013). Um dos problemas é a interferência no solo promovidas pelo manejo incorreto na qual o mesmo fica exposto à ação de ventos, chuvas, raios solares e altas temperaturas, que destroem a estrutura do solo da propriedade, e que se contribui com a perda de capacidade produtiva.

De acordo com Amaral et al. (2016), o município de Castanhal pertencente ao nordeste paraense tem adquirido o papel de centro sub-regional devido as suas características de natureza demográfica, econômica e política, tendo certa autonomia da capital do estado, chamando a atenção para as questões socioambientais mantidas entre a capital e o município de Castanhal. Entretanto, o meio ambiente encontrase em estágio avançado de degradação, com existências de poucos remanescentes de florestas, causados pela extração da madeira, queimadas e pela não preservação do meio ambiente prejudicando a agricultura de subsistência.

Embora protegidas legalmente desde a década de 60 , nem mesmo as áreas de preservação permanente (APP) foram poupadas nesse processo de degradação. Hoje, uma grande parte da população de castanhal reside em áreas rurais, onde parte da água potável utilizada para o consumo humano vem de nascentes que, infelizmente, estão sendo contaminadas pela população.

Atualmente, existe uma grande preocupação da sociedade com a questão da preservação e conservação dos recursos naturais, principalmente da água, que proporcionam bem-estar humano. Contudo, se não houver esforços entre o poder público e os habitantes em combater essa degradação, as novas gerações podem sofrer com a escassez da água. Este trabalho teve como objetivo a implantação de técnicas de conservação e a proteção de solos, a pequenos produtores rurais, diagnosticando a recuperação dos solos degradados através de atributos químicos, físicos e biológicos, tendo em vista à readequação da propriedade as técnicas de uso do solo de forma sustentável. 


\section{METODOLOGIA}

A propriedade está localizada na Latitude $01^{\circ} 14^{\prime} 55,70^{\prime \prime}$ S e Longitude $47^{\circ} 57^{\prime} 03,56^{\prime \prime} \mathrm{W}$ no $\mathrm{Km} 05$, na agrovila de São Raimundo pertencente ao município de Castanhal no estado do Pará. Segundo Alves (2012) as margens da rodovia PA-Trans-Castanhal, região do nordeste do Pará que se localiza a $69 \mathrm{~km}$ da capital (Figura 1).

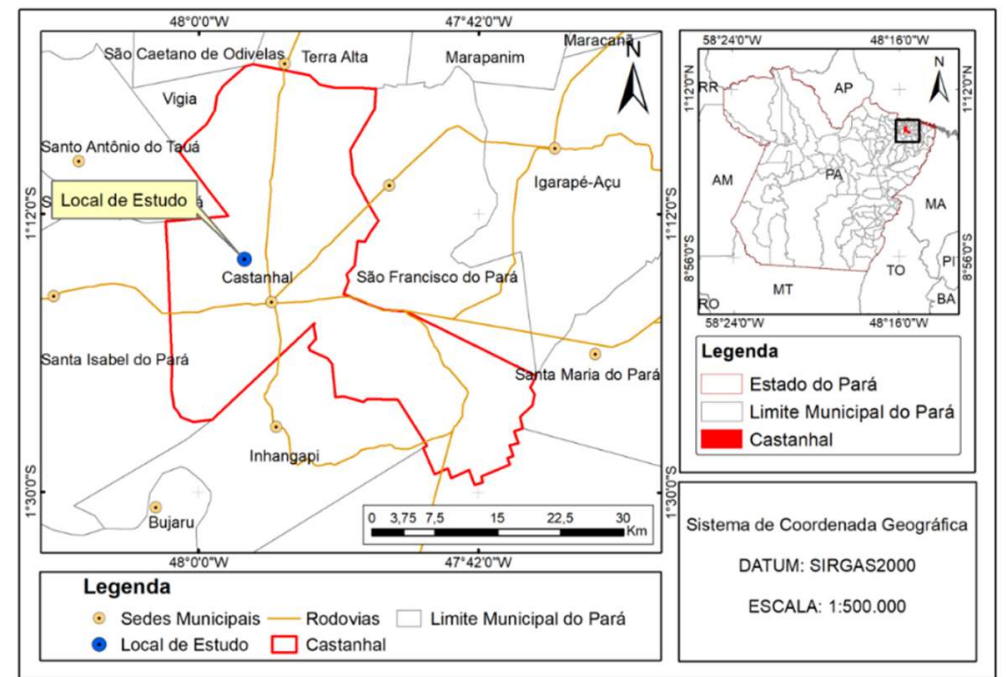

Figura 1: Mapa do município de Castanhal e Localização da área de Estudo.

O clima do município é definido como Equatorial Ami, classificação de Koppen, com temperatura média de $25^{\circ} \mathrm{C}$ e máxima de $40^{\circ} \mathrm{C}$. A estação mais chuvosa ocorre de dezembro a maio e a menos chuvosa vai de junho a novembro, com umidade relativa do ar entre $85 \%$ e $90 \%$ Santos et al. (2006). O índice médio pluviométrico anual é de $2.604,4 \mathrm{~mm}$ e a quantidade de dias chuvosos durante o decorrer do ano chega em torno de 208 dias (SANTOS et al., 2012).

De acordo com a EMBRAPA (1999), a vegetação é composta, predominantemente, pela floresta equatorial subperenifólia densa. Portanto é caracterizada por apresentar fisionomia e estrutura variadas, na qual algumas espécies perdem as folhagens parcialmente na época de maior estiagem. Geralmente, é denominado de floresta densa de terra firme ou floresta tropical úmida com este tipo de revestimento florístico (SUDAM, 1988).

De acordo com a classificação adotada pelo Instituto Brasileiro de Geografia e Estatística (IBGE) esta vegetação é classificada como floresta ombrófila densa (VELOSO et al., 1982). Estas classificações são atribuídas à vegetação primária. A floresta equatorial higrófila de várzea margeiam os percursos d'água em menor proporção. E se configura por apresentar espécies que não perdem folhas em nenhuma época do ano. É importante este tipo de cobertura vegetal, principalmente pela grande concentração de espécies de palmeiras como o açaizeiro (Euterpe oleracea, Mart.) e buritirana (Mauritia aculeata, H.E.K.). O Instituto Brasileiro de Geografia e Estatística classifica esta vegetação como floresta ombrófila densa de planície aluvial (VALENTE et al., 2001). Em relação ao relevo do município é plano, com declividade que varia entorno de $0 \%$ a $3 \%$. Entretanto, ocorrem setores com relevo suave ondulado a ondulado com declividade variando de aproximadamente 3\% a 15\% (EMBRAPA, 1999).

Os solos que frequentemente são encontrados no Município de Castanhal são o Argissolo Amarelo 
Distrófico, o Argissolo Vermelho Amarelo Distrófico concrecionário, o Neossolo Flúvico Distrófico, o Gleissolo Háplico Distrófico e o Espodossolo Ferrocárbico Hidromórfico, outros tipos de solos que ocorrem em segundo plano nas intermediações são o Latossolo Amarelo Distrófico, o Neossolo Quartzarênico Hidromórfico e o Latossolo Vermelho-Amarelo Distrófico concrecionário (VALENTE et al., 2001).

\section{Economia}

De acordo com a Doutora em Economia Aplicada Maria Lúcia Bahia, baseada em dados do IBGE (2010), afirma que a economia do município está diretamente ligada a atividades de serviços, seguida pela industrialização e representando uma pequena escala a agropecuária. Segundo Miranda (2012) Castanhal apresenta um grau de desenvolvimento mais elevado que outras cidades localizadas na região metropolitana de Belém, dada a presença de 180 indústrias de transformação, 4 serviços industriais de utilidade pública, 959 estabelecimentos comerciais e 458 estabelecimentos de serviços em geral, a exemplo de hotéis e restaurantes. Em Castanhal, a produção de cereais é inexpressiva e as distâncias tornam a importação de grãos ou ração farelada inviáveis, as pastagens constituem a principal fonte de alimentos do rebanho leiteiro que é de baixa produtividade. A exploração leiteira é uma importante atividade pequenos produtores, devido à falta de alternativas agrícolas mais rentáveis (BENDAHAN et al., 2000)

\section{Histórico da Agrovila}

A agrovila São Raimundo originou-se com a chegada de algumas famílias cearenses após o início do povoamento do município de castanhal. Entre as famílias, os casais Rodolfo Carneiro e Maria Carneiro se destacaram por trazerem a imagem de São Raimundo Nonato, ao qual construíram uma capela por serem devotos desde santo e dando o nome a comunidade de Ramal São Raimundo, que antes era conhecido como Cabeceira do Rio Apeú.

Com o passar dos anos e com o crescimento do município, no dia 9 do mês de dezembro do ano de 1994, o Ramal São Raimundo, foi elevado à categoria de Agrovila São Raimundo, localizada no município de Castanhal estado do Pará, no KM 05 da Rodovia Transcastanhal. A população é de aproximadamente 328 habitantes. As maiorias das famílias moram em casa própria feita de alvenaria. Na comunidade são desenvolvidos alguns aspectos culturais, bem como, a festividade de São Raimundo Nonato que iniciasse dia 22 e vai até 31 de agosto de todos os anos realizado pela diocese de Castanhal com a ajuda da comunidade, grupo de catequese.

A mesma tem como atividades comerciais a produção de hortaliças por algumas famílias, o trabalho em fazendas com o cuidado da terra e dos animais e o comercio de alimentos e bebidas em balneários da localidade. Alguns moradores trabalham em empresas no centro da cidade e como domésticas na casa de famílias. Na agrovila existe uma associação de moradores que foi fundada no dia 31 de janeiro de 1994, com a finalidade de trazer melhorias e de manter o intercâmbio com as associações pertencentes a qualquer parte do território nacional, com isso a associação tem uma assembleia geral que é constituída de associados maiores de 18 anos. 
No ano de 1994, quando a família adquiriu a propriedade se depararam com um conjunto de problemas. A área estava descampado, havia presença de poucas árvores na propriedade, a espaço era quente, sem ventilação, havia presença de pouquíssimos animais, o solo era bastante arenoso e cansado, pois os proprietários antigos não faziam nenhum tipo de manejo do solo, portanto plantaram por diversas vezes a cultura da mandioca, devido à inclinação o solo era bastante lavado e dificultava o plantio e formação de seus roçados, a nascente estava quase desaparecendo devido à declividade do solo o mesmo sofria com a lixiviação das águas das chuvas que cada vez mais aterravam a nascente, favorecendo assim que num futuro bem próximo não existisse mais o igarapé.

O Nordeste paraense abrange parte significativa do litoral paraense, incluindo alguns municípios que vai de São João da Ponta ao município de Viseu e que também pega parte da área interiorana denominada de Região Bragantina. A extensão da Bragantina inclusa na Região Nordeste do Pará se estende de Castanhal às intermediações de Bragança e Viseu (AMARAL et al., 2016).

Os proprietários residem na localidade há 23 anos, quando chegaram à área possuía somente um pequeno córrego na extremidade do sitio, existia apenas uma pequena área de mata secundária com cerca de $20 \mathrm{~m}$, todo o restante da área era de um adensado capoeirão oriundo de um antigo plantio de mandioca, o solo possuía características que muito o assemelhavam com areia branca, o córrego que existia na área sofria constante lixiviação devido o terreno ser bem inclinado e a falta de árvores nas encostas do leito que também facilitava o assoreamento das nascentes de água, ou seja, a área consistia em uma grande área degradada e lixiviada, na qual não existia a presença de culturas que pudessem ajudar na produção de matéria orgânica, e assim basicamente o solo não era provido de nenhuma proteção contra ações diretas das chuvas fragilizando assim sua estrutura e a característica.

\section{Coletas de Dados}

O presente trabalho baseou-se, primeiramente, na pesquisa exploratória de dados secundários, obtidos por meio de consulta bibliográfica. A coleta de dados em fonte primária foi realizada através de entrevista pessoal individual do tipo não estruturada e observações diretas. O estudo de caso é uma investigação atual, onde o fenômeno pesquisado e o contexto não estão visivelmente evidentes, precisando de respostas contundentes. Segundo Prodanov (2013) comenta que a pesquisa exploratória proporciona maior familiaridade com o caso a ser estudado, o que poderá ocorrer através de levantamento bibliográfico, entrevistas com pessoas esclarecidas do problema pesquisado. Em regra, assume a forma de pesquisa bibliográfica e estudo de caso.

\section{RESULTADOS E DISCUSSÃO}

A pesquisa iniciou pela análise da situação atual da propriedade, para depois comparar com as informações coletadas dos proprietários de quando adquiriram a propriedade em 1994, onde se observou mudanças na infraestrutura de produção e a distribuição do arranjo do uso alternativo do solo existente hoje. 


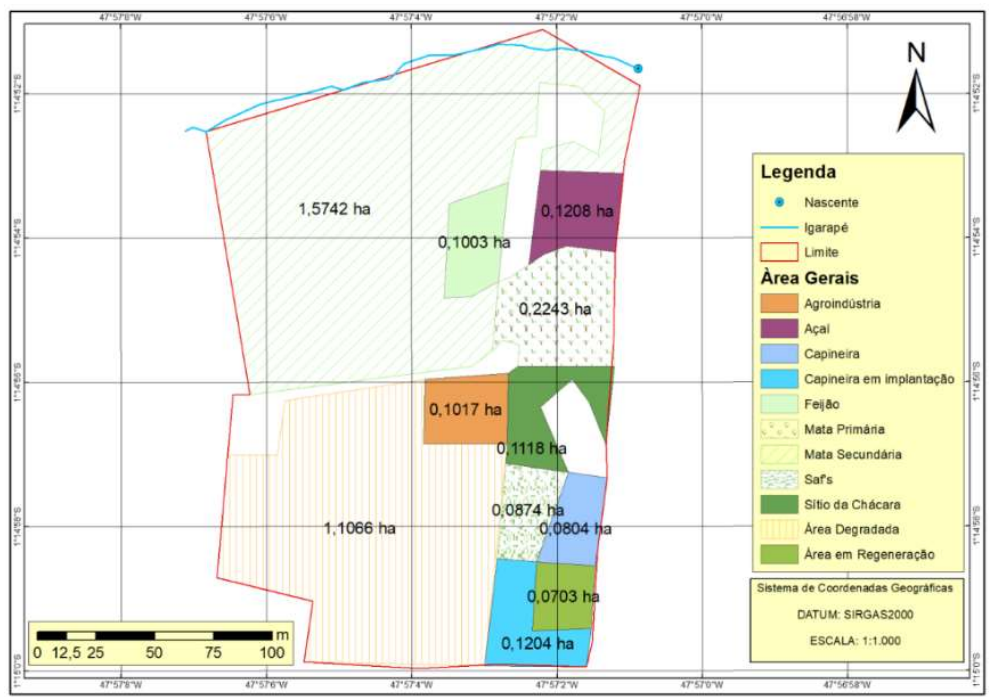

Figura 2: Croqui da Agrovila São Raimundo de Castanhal (PA) com seus respectivos usos do solo.

Grande parte das propriedades ao entorno possuem tal infraestrutura, geralmente apresentando sérios problemas de disponibilidade de mão de obra, máquinas e equipamentos, instalações adequadas e, até mesmo, meios de transporte. O igarapé que corta várias propriedades adjacentes não apresenta a mesma qualidade e quantidade de água da propriedade Sítio Recanto dos Rocha devido a não realização da proteção da mata ciliar do entorno, que veem sendo realizada desde a compra da propriedade.

As famílias da Agrovila São Raimundo apresentam baixa organização social, sendo a agricultura familiar e a coleta de produtos da floresta suas principais atividades de subsistência. A principal fonte de renda vem da agricultura, especialmente da mandioca seguida pelo milho, feijão e espécies de olericultura que consegue se desenvolver em poucos dias para serem comercializadas. Estas culturas compõem a base da alimentação familiar.

Parte destas famílias tem como atividade principal o comércio, o que thes permite um circuito de comercialização diferente do praticado pelos agricultores que, por sua vez, negociam sua produção com atravessadores. Que compram seus produtos por preços baixos, para comercializarem na feira, e poucos agricultores conseguem produzir e levar suas culturas para comercio local ou até mesmo a chamada feira do agricultor que se localiza no centro de Castanhal atraindo diversas clientelas que são acostumadas a fazer suas compras nas feiras no final de semana. Esta feira já existe há mais de 30 anos e a sua finalidade é reunir os produtores rurais num único local para realizarem a venda de seus alimentos, de forma que deixe uma margem de lucro relevante para os produtores, para que não dependa de atravessadores para escoar a sua produção.

\section{Área de agricultura}

Com o fechamento de um caminho antigo na propriedade e utilizando outra via de acesso, a família aproveitou a área que era descampada para fazer seu roçado, e nessa área plantaram milho, feijão, melancia, maxixe, quiabo e macaxeira (Tabela 1). Depois da colheita, toda matéria orgânica (pés de milho seco, restos cultura de feijão), são deixadas na área para decompor e incorporar ao solo como ciclagem de nutrientes.

Partes dessas culturas que não eram comercializadas serviam como alimento a família e outra parte 
era destinada para os animais como o suíno e aves, que consumiam uma proporção considerável do milho e uma parte do que sobrava das melancias e macaxeiras, pois consideravelmente não conseguiam atingir os pesos satisfatórios, que na qual tinham baixo custo de sua alimentação, e que posteriormente fossem comercializados ou consumidos pela família ao atingir o tamanho e peso ideal.

As frutas produzidas na propriedade são vendidas de forma "in natura", que segundo Alves (2001) tornam o produto menos viável economicamente do que se fosse vendido na forma de polpa de frutas ou doces e geleias. Os produtos, como a abóbora, banana, castanha de caju, maracujá e o açaí encontram comércio dentro da comunidade.

Tabela 1: Preço em reais (R\$) de venda e a quantidade de produtos agrícolas do Sítio Recanto dos Rocha.

\begin{tabular}{llllll}
\hline Produto & Nome científico & Quantidade & Preço (R\$) & Venda (R\$) & Retorno (\%) \\
\hline Manga & Mangifera indica L. & 200 & 0,4 & 80 & 3,8 \\
Ingá & Inga sessilis (Vell.) Mart. & 320 & 0,2 & 64 & 3,04 \\
Pupunha & Bactris gasipaes Kunth & $25 \mathrm{Kg}$ & 5 & 125 & 5,93 \\
Abacaxi & Ananas comosus L. Merril & 40 & 1,5 & 60 & 2,85 \\
Cupuaçu & Theobroma grandiflorum (Willd. ex Spreng.) K. Schum. & $15 \mathrm{Kg}$ & 8 & 120 & 5,69 \\
Limão & Citrus limon L. Burmann f. & 100 & 0,2 & 20 & 0,95 \\
Laranja & Citrus sinensis L. Osbeck & 100 & 15 & 15 & 0,71 \\
Tangerina & Citrus reticulata Blanco & 100 & 12 & 12 & 0,57 \\
Abóbora & Cucurbita moschata Duch. & 25 & 0,9 & 22,5 & 1,07 \\
Banana & Musa spp & 20 & 3 & 60 & 2,85 \\
Jaca & Artocarpus heterophyllus Lam. & 12 & 3 & 36 & 1,71 \\
Castanha de cajú & Anacardium occidentale L. & 22 & 2 & 44 & 2,09 \\
Açaí & Euterpe oleracea Mart. & 18 & 20 & 360 & 17,08 \\
Acerola & Malpighia punicifolia L. & 10 & 2 & 20 & 0,95 \\
Maracujá & Passiflora edulis f. flavicarpa & 20 & 2,5 & 50 & 2,48 \\
Macaxeira & Manihot esculenta Crantz & $50 \mathrm{Kg}$ & 2 & 100 & 4,96 \\
Melancia & Citrullus lanatus (Thunb.) & $80 \mathrm{Kg}$ & 1 & 80 & 3,96 \\
Maxixe & Cucumis anguria L. & $40 \mathrm{Kg}$ & 3 & 120 & 5,95 \\
Feijão-caupi & Vigna unguiculata (L.) Walp. & $100 \mathrm{Kg}$ & 3 & 300 & 14,87 \\
Quiabo & Abelmoschus esculentus L. Moench. & $12 \mathrm{Kg}$ & 5 & 60 & 2,97 \\
Milho & Zea mays L. & $300 \mathrm{Kg}$ & 1,2 & 360 & 17,84 \\
& VALOR TOTAL & & & $\mathbf{2 . 1 0 8 , 5 0}$
\end{tabular}

Os produtos como a manga e o ingá são comercializados em quantidades razoáveis a um valor muito baixo, desta forma parecendo desfavorável ao produtor, mas quando associados com outros produtos da propriedade como a jaca e a acerola, compensa a venda. A propriedade não produz frutos em grande quantidade, devido à diversidade de espécies na mesma. Devido a isso precisam agregar todos os diferentes frutos produzidos para que assim e consigam obter uma renda de $\mathrm{R} \$ \mathbf{2 . 1 0 8 , 5 0}$ (Tabela 1 ).

\section{Área de floresta}

Ainda no primeiro ano a família mudou o caminho que levava até a casa do sitio, pois, a mesma cortava o sitio num ângulo de 45 graus, diminuindo assim a quantidade de terra aproveitável. Os proprietários decidiram fechar a antiga entrada com cerca e aproveitaram um caminho antigo para fazer uma nova estrada que passa no limite do terreno. 0 caminho foi fechado pela família para aumentar a área de produção do milho, feijão, macaxeira, melancia que eram destinados na alimentação dos mesmos, alimentação dos animais e o excedente destinado à comercialização para complemento da renda familiar e manutenção da propriedade. 
Devido à problemática de não haver árvores nem animais e o calor ser muito intenso, à família resolveu plantar algumas espécies florestais para diminuir a temperatura e ao mesmo tempo tentar fazer com que a água da chuva não aterrasse a nascente. No entorno da cerca plantaram mudas de andiroba (Tabela 2), já no ano seguinte foi observado que algumas espécies começaram a nascer no entorno do novo roçado, porém sem vigor.

A família utilizou esse espaço para formação de seus plantios trabalhando a agricultura até o terceiro ano, após esse período de três anos a família abandonou o espaço e permitiu que a área se recuperasse por conta própria, deixando a regeneração natural desenvolver. Hoje, contabilizam-se algumas espécies de uso comercial, medicinal e comestíveis na propriedade conforme a Tabela 2.

Tabela 2: Composição florística e grau de comercialização (GC) de espécies madeireiras que ocorrem em uma propriedade rural de aproximadamente 3,7 ha de floresta secundária no Município de Castanhal-PA.

\begin{tabular}{|c|c|c|}
\hline Família/Nome científico & Nome vulgar & USO \\
\hline \multicolumn{3}{|l|}{ Bignoniaceae } \\
\hline Jacaranda copaia (Aubl.) D. Don & Parapara & $\mathrm{AL}, \mathrm{MA}, \mathrm{ME}$ \\
\hline Handroanthus albus (Chamiso) Mattos & Ipê amarelo & $A L, M A, M E, A R$ \\
\hline \multicolumn{3}{|l|}{ Caryocaraceae } \\
\hline Caryocar villosum (Aubl.) Pers. & Piquia & $A F, A L, M A, M E$ \\
\hline Caryocar glabrum (Aubl.) Pers. & Piquiarana & $A F, A L, M A, M E$ \\
\hline \multicolumn{3}{|l|}{ Celastraceae } \\
\hline Goupia glabra Aubl & Cupiúba & AL, MA, ME \\
\hline \multicolumn{3}{|l|}{ Humiriaceae } \\
\hline Endopleura uchi (Huber) Cuatrec & Uxi & $\mathrm{AF}, \mathrm{AL}, \mathrm{MA}, \mathrm{ME}$ \\
\hline \multicolumn{3}{|l|}{ Lecythidaceae } \\
\hline Lecythis lurida (Miers.) S. A. Mori & Jarana & $A F, A L, M A, M E$ \\
\hline Lecythis pisonis Cambess & sapucaia & $A F, A L, M A, M E, A P$ \\
\hline \multicolumn{3}{|l|}{ Leguminosae } \\
\hline Hymenolobium petraeum Ducke & Angelim pedra & $A L, M A, M E$ \\
\hline Inga paraensis Ducke & Ingá-vermelho & $\mathrm{AF}, \mathrm{AL}, \mathrm{MA}, \mathrm{ME}$ \\
\hline Vouacapoua americana Aubl., & Acapu & $\mathrm{AL}, \mathrm{MA}, \mathrm{ME}$ \\
\hline Inga sessilis (Vell.) Mart. & Inga ferradura & $A F, A L, M A, M E$ \\
\hline \multicolumn{3}{|l|}{ Meliaceae } \\
\hline Carapa guianensis Aubl. & Andiroba & $\mathrm{AL}, \mathrm{MA}, \mathrm{ME}$ \\
\hline Swietenia macrophylla king & Mogno & $\mathrm{AL}, \mathrm{MA}, \mathrm{ME}$ \\
\hline
\end{tabular}

Nota: USO - Medicinal (ME), Madeira (MA), Alimentação Humana (AH), Alimentação Fauna (AF), Arborização e paisagismo (AP).

A sapucaia ou castanha sapucaia é uma árvore de médio e grande porte, nativa do Brasil, que chama a atenção pelo seu porte e pela coloração que sua copa adquire na primavera. Apresenta um fruto grande que abriga muitas sementes (castanhas) oleaginosas e comestíveis. Além de fornecer frutos comestíveis, é cultivada como planta ornamental na Região Sudeste do Brasil. A madeira é de excelente qualidade e usada para muitos fins. As cascas são utilizadas popularmente para tratamento de diarreias, e as folhas para revigorar o músculo cardíaco, diuréticas e podem ser usadas no banho contra coceira.

O ipê amarelo possui propriedades medicinais que podem ser extraídas da casca, das folhas, dos ramos jovens e das flores. Seus benefícios podem ser usados para combater dermatoses, coceiras, inflamações da gengiva e da garganta, infecções renais, dermatites, varizes e algumas doenças dos olhos. A madeira e pesada, com cerne escuro, adquire grande valor comercial na marcenaria e carpintaria, podendo ser usada na fabricação de dormentes, moirões, pontes, postes, eixos de roda, varais de carroça, moendas de cana, etc. 
O acapu é uma espécie florestal que foi bastante explorada para fabricação de tacos de bilhar, assoalhos, vigas, tabuado, dormentes, laminados, lambris, móveis e construções externas, podendo ser usada, também na Construção civil e naval, carpintaria e marcenaria. $O$ acapu apresenta propriedades medicinais que são utilizados para o combate de úlceras crônicas, apresenta ação anti-inflamatória, antisséptica, cicatrizante e fortificante neuromuscular, podendo ser indicado para tratar diarreia, infecções no útero e ovário e úlcera crônica.

Segundo Souza Filho et al. (2000) o crescente interesse pelos sistemas agroflorestais como alternativa para a exploração de áreas tropicais, especialmente onde predominam os solos ácidos e de baixa fertilidade, tem contribuído para manter um equilíbrio sustentável no meio ambiente em uso. A utilização de espécies arbóreas com características desejáveis é fundamental para a estabilidade e o sucesso do sistema. Paralelamente, espécies com atividade alelopática podem desempenhar papel crucial na estabilidade dos sistemas agroflorestais, em especial na redução da infestação de plantas invasoras e no combate de doenças. A andiroba é uma árvore de grande porte que apresenta fuste cilíndrico e reto. A casca é grossa, tem sabor amargo e desprende-se facilmente em grandes placas, possui aplicação na marcenaria, na carpintaria e na medicina popular como repelente natural de insetos, antissépticos, cicatrizante e antiinflamatório.

De acordo Mendonça et al. (2007) a andiroba apresenta uso múltiplo, com grande aceitação na fabricação de móveis, construção civil, lâminas e compensado e as sementes para extração de óleo. Na Amazônia o óleo de andiroba tem uma importante participação na economia regional, principalmente, na medicina popular. O óleo e seus subprodutos, tais como sabonetes e velas são geralmente encontrados em feiras livres. O óleo também tem sido comercializado para outras regiões do país, além de ser exportada, principalmente, para indústria de cosméticos da França, Alemanha e dos Estados Unidos.

\section{Área de criação de animais}

Os suínos foram trazidos da região das ilhas que pertencem ao município de Belém (Ilha das onças, Uriboca, Paquetá e llha nova) cuja raça é nativa dessa ilha. No início, acreditou-se que seriam da raça cateto ou catitu (Pecari tajacu), porém, após pesquisas e análises junto à pesquisadora da EMBRAPA, chegou-se à conclusão que realmente são animais rústicos como os selvagens, portanto ao longo de seu processo de domesticação cruzaram com animais de raças industriais.

As galinhas foram adquiridas de vizinhos, em feiras do próprio município e com parentes e amigos da família. Não caracterizam uma raça definida, sendo conhecida popularmente como caipira. Contudo, no ano de 2017, foram adquiridos galos e galinhas da raça índio gigante, oriundos de um produtor rural de Tomé-Açú, para produzir descendentes para futuros consumos e/ou comercialização. Da mesma forma os perus, também chegaram à propriedade vinda de propriedades de parentes que residem na Agrovila Três de Outubro e Timboteua, da mesma forma aparentemente não possuem uma raça definida, sendo conhecidas apenas como peru preto e peru branco.

Os peixes são na grande maioria tilápias, adquiridas na feira do peixe vivo na igreja de São Francisco 
em Castanhal. Após a compra alguns foram consumidos pela família e outros foram colocados em tanque escavado na propriedade, feitos de sacos de ráfia, entretanto após alguns dias, observou-se que apareceram vários alevinos e após isto a propriedade nunca mais deixou de produzir peixes.

Tabela 3: Criação de animais domésticos que ocorrem em uma propriedade rural de aproximadamente 3,7 ha de floresta secundária no Município de Castanhal-PA.

\begin{tabular}{llllll}
\hline PRODUTO ANIMAL & QUANT. & MEDIDA & PREÇO & VALOR & RETORNO (\%) \\
\hline SUINO & 1 /MÊS & 60 KG & 15,00 & 900,00 & 52,63 \\
GALINHA & 12 / MÊS & UNIDADE & 40,00 & 480,00 & 28,07 \\
PERÚ & 3 / MÊS & UNIDADE & 80,00 & $\mathbf{2 4 0 , 0 0}$ & 14,04 \\
PEIXE & 10 KG / MÊS & KG & 9,00 & 90,00 & 5,26 \\
\hline VALOR TOTAL & & & & $\mathbf{1 . 7 1 0 , 0 0}$ & \\
\hline
\end{tabular}

As tabelas apresentadas refletem o preço de alguns produtos, no entanto, este valor está baseado em preços que os agricultores oferecem na feira do agricultor de Castanhal. Corroborando com a pesquisa de campo, percebe-se que o volume de vendas dos animais proporciona um resultado positivo (Tabela 2), haja visto que o custo de produção é baixo.

Todos os animais mencionados acima recebem ração que é adquirida com a venda dos mesmos, e de produtos oriundos da propriedade como: macaxeira, milho, abóbora, manga e os excedentes são vendidos no comercio local. Há uma frequente procura atravessadores por animais, na qual alguns deles destinam esses animais nas feiras populares como a do produtor rural em Castanhal, e em feiras de outros municípios e muita das vezes não há necessidade do produtor levar seus animais até as feiras para serem comercializadas. Com isso, a margem de lucro total foi de $\mathrm{R} \$ 3.818,50$. Aqui não foi possível verificar a dedução das despesas para calcular os custos fixos.

\section{Peixes exóticos, ornamentais e silvestres}

A criação de peixes iniciou através de projetos em parceria com a Universidade para que fosse criado um local de estudo para os alunos dos cursos técnicos. A família optou somente por essas duas espécies o Guppy (Poecilia reticulata) e o Véu de noiva (Carassius auratus Linnaeus) devido alguns fatores que julgam importantíssimos como: beleza, adaptabilidade e valor agregado, pois são animais que variam em diversas cores e devido a isso encantam os amigos visitantes e frequentadores da propriedade. A adaptabilidade desses animais em águas com PH baixo e $\mathrm{PH}$ pouco elevado respectivamente, sendo assim animais fáceis de criar e de se reproduzir, tornando os mesmos excelentes para criação. Esses animais são comercializados, por visitantes, amigos e frequentadores da propriedade. Em alguns casos esses visitantes compram bastante exemplares e negociam com comerciantes que trabalham com peixes ornamentais, e sua comercialização também potencializa a renda da família.

A Tilápia (Oreochromis niloticus) foi criada por ser uma espécie de alta resistência, pois tem a capacidade de se adaptar em lugares que outras espécies não sobreviveriam ou em condições que outros animais não se adaptariam, e também por conseguirem se reproduzir facilmente. Além disso, sua criação poder ser feita em pequenas áreas, tanques de alvenaria, tanque escavado no chão e outros. No entanto uma parte serve de alimentação da família e a outra é destinada a comercialização. 
Os proprietários notaram a presença de algumas aves nativas que não se viam nos primeiros anos no sitio principalmente o arancuã (Ortalis guttata), coleiro (Sporophila caerulescens), caboco-lino (Sporophila bouvreuil), curió (Oryzoborus angolensis), beija flor (Trochilidae), pintada (Sporophila beltoni), sabiá (Turdus), pipira (Tachyphonus rufus), bem-te-vi (Pitangus sulphuratus), juntamente com outras espécies de mamíferos como a mucura (Didelphis marsupialis) e o morcego (Chiroptera) que na qual acreditam ser um dos agentes responsáveis pela ajuda do arranjo de muitas espécies que não se viam mais na região, alguns roedores foram presenciado como os ratos (Muridae), e algumas outras espécies de animais peçonhentos como o escorpião (Scorpiones), e a jararaca (Bothrops jararaca). Foi observado a presença de outros animais como a preguiça (Bradypus variegatus), macaco soim (Saguinus fuscicollis), tatupeba (Euphractus sexcinctus), jabuti (Chelonoidis carbonaria) e o quati (Nasua), que durante muitos anos foram extintos da propriedade, e através de um simples ato de recuperação da floresta consegue-se ver e presenciar os sons dos animais no decorrer do dia na mata recuperada.

Segundo Ribaski et al. (2001) a recuperação de áreas degradadas era feita através da revegetação, com intervenção no substrato, vegetação e na fauna, visando o surgimento de um bosque. Hoje, a recuperação baseia-se no princípio da sucessão ecológica que consiste na implantação de espécies pioneiras, iniciais e tardias até chegar ao clímax; essa mudança temporal da composição florística se dava de forma gradativa, culminando em sistemas mais estruturados, diversos e complexos que os iniciais.

A difícil tarefa de transformar áreas degradas em florestas sustentáveis precisam que processos ecológicos sejam efetivados com característica que promovam as interações entre fauna e flora para promover condições de auto sustentabilidade à floresta implantada (BARBOSA, 2000). A propriedade durante muitos anos apresentava solo degradado e descampado e com pouco nutriente, devido ao constante desmatamento e queimadas para transformarem em áreas de pastos. A exposição do solo em épocas de chuva provocava erosão e assoreamento dos rios e desequilíbrios na flora e fauna.

Durante os primeiros anos a família trabalhou na preservação da nascente que estava quase desaparecendo, plantou nas margens espécies de ingá e açaí para minimizar a lixiviação. Os proprietários resolveram fazer uma barragem com o intuito de aumentar a altura da lâmina de água, e assim foi feito represaram a água e após 5 anos os açaizeiros estavam estabelecidos os pés de açaí se multiplicaram no entorno de todo o curso d'água.

A figura 3 mostra a propriedade em 1997, a área em cor rosa corresponde a área da nascente na qual se mostra com um alto nível desmatamento. Porém não resolveu por completo a problemática da lixiviação, devido a isso resolveram colocar pneus na borda do igarapé (muros de arrimo) e no decorrer de toda a propriedade em lugares onde foi observado que o fluxo de água era bastante significativo foram feitas barreiras com garrafas pet, e nessas áreas também foram plantados pés de açaí e ingá. Essas espécies foram escolhidas com duas razões específicas, o ingá é de rápido desenvolvimento (MATA, 2006), é um vegetal que facilmente e rapidamente forma galhos que por sua vez minimizariam o impacto da água das chuvas no solo, sua raiz a um primeiro momento minimizou o excesso de solo que era lixiviado em sentido ao igarapé.

A figura 4 representa a propriedade em 2017. Nitidamente é visto que na área da nascente houve 
processo de recuperação, devido as práticas adotadas para conter o processo de degradação. Num segundo plano, esse sistema implantado, fez sombreamento, para o açaí que realmente era a espécie desejada devido sua raiz ser mais indicada para este tipo de caso, uma vez que suas raízes saem em busca de alimento e facilmente se expandem por toda a área reduzindo a problemática da lixiviação e encontra partida fornecendo a família mais um alimento e consequentemente renda através de seus frutos.

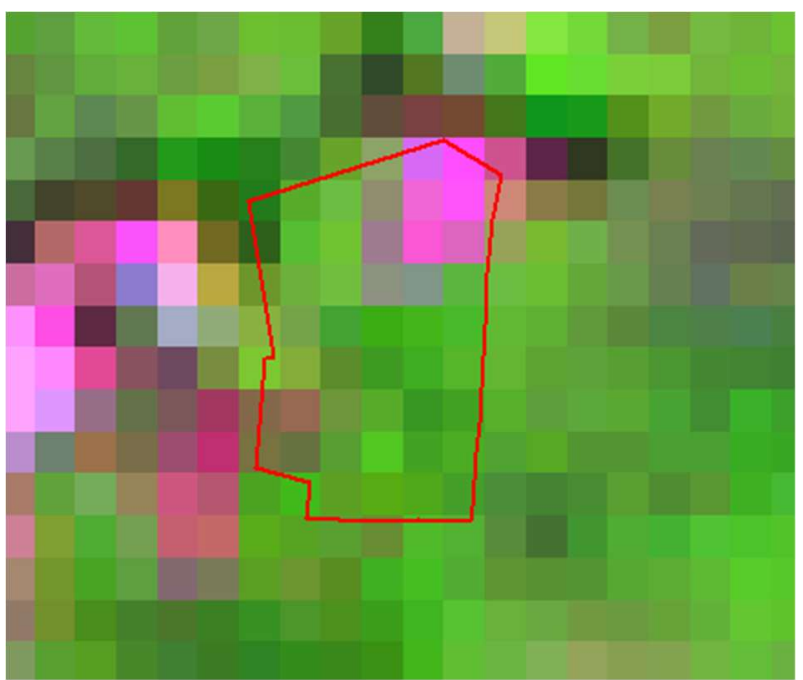

Figura 3: Propriedade em 1997.

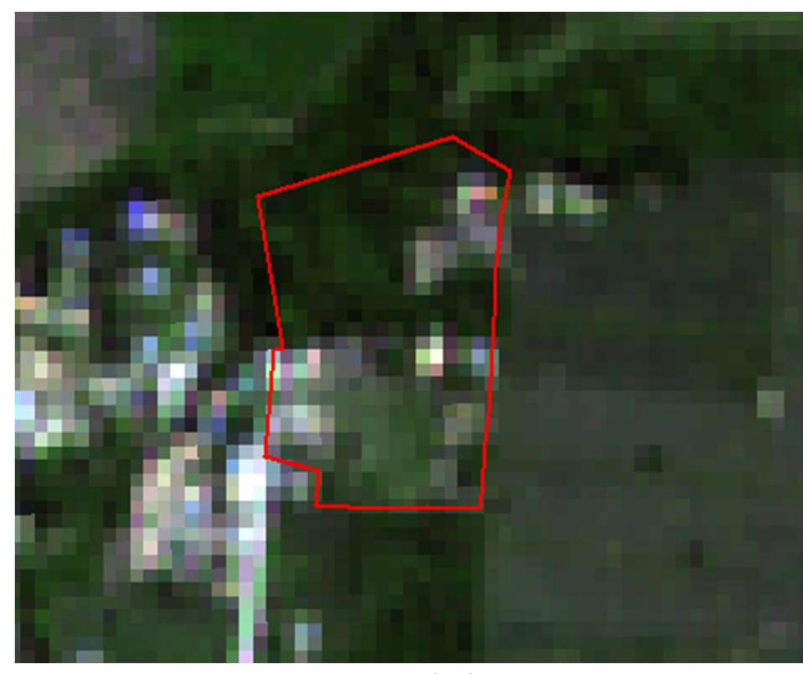

Figura 4: Propriedade em 2017.

O ingá foi plantado com o intuito de se estabelecer proteção ao solo com a formação de uma copa significativa que impede o impacto direto das chuvas com o solo, fornecendo matéria orgânica abundante, sombra para o açaí nos primeiros anos além de fixar nitrogênio no solo. Ribaski et al. (2001) comentam que áreas degradadas pela água de chuvas, podem ser recuperadas pela utilização de práticas agroflorestais como barreiras vivas, formação lenta de terraços para uso agrícola, estabilização de voçorocas, cultivos em renques, árvores em contorno e árvores sobre curvas de nível, entre outras.

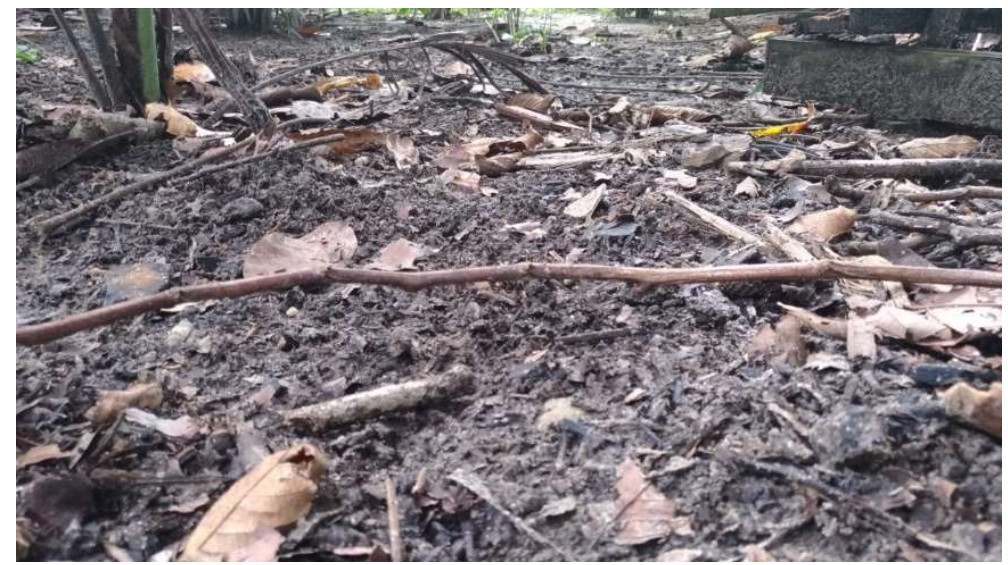

Figura 5: Imagem superficial do solo apresentando uma camada de liteira.

Após isto, foi observado que a água das chuvas já não causava problemas diretos no igarapé e o solo começou a mudar sua coloração. A ciclagem de nutriente advindo da matéria orgânica dos vários componentes implantados na área passou a melhorar o solo e consequentemente os plantios. Hoje, o solo está diferente e conservado quando comparado com o mesmo solo das propriedades ao entorno. Existe propriedade em toda a extensão do igarapé, porém, quando comparado visualmente com os solos da 
margem do igarapé é nítida a diferença, tanto de qualidade, quanto de conservação, na qual se pode observar uma camada superficial no solo de folhas e galhos se decompondo (Figura 5).

\section{Área Recuperada}

Depois de um longo processo de utilização do uso do solo, a área que tinha grande características de degradação e que sofria por ter passado vários períodos sendo cultivada por uma única cultura pelos antigos moradores. Com a chegada dos novos residentes no terreno, tiveram de imediato a ideia de recuperar a nascente que passa dentro da propriedade, criando um muro de arrimo para impedir o assoreamento do igarapé.

Foram plantadas algumas espécies com raízes fasciculadas para servir de proteção dos mananciais. Esse processo teve como objetivo a preservação do solo e o combate à erosão, proporcionando, melhoria nas características físicas do solo, aquelas relativas à capacidade de infiltração da água da chuva ou da irrigação, que determinam maior disponibilidade de água na nascente em quantidade e estabilidade ao longo do ano, incluindo a época das secas. No entanto, todo este processo de recuperação tem entorno de 23 anos onde se observa, hoje, água cristalina (Figura 6).

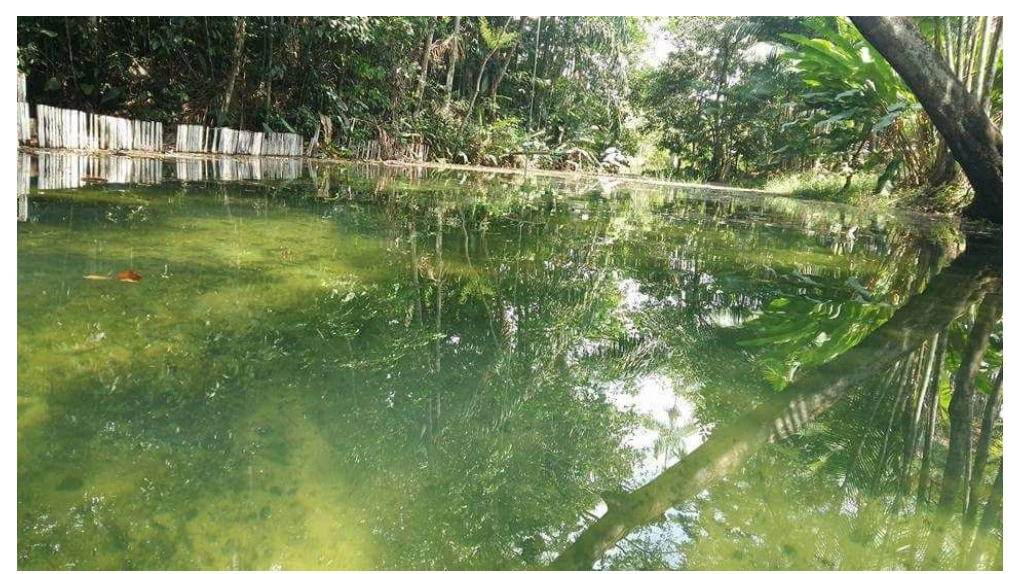

Figura 6: Imagem das águas Cristalinas do Igarapé.

A área total da propriedade encontra-se em processo de recuperação de seus recursos naturais. Hoje, a propriedade possui uma área de 0,07 ha que tem entorno de 7 anos, que na qual se encontra em fase de recuperação. E que podemos observar pela imagem, alguns galhos e folhas e troncos finos. A obtenção de benefícios socioeconômicos e ambientais pelos proprietários da fazenda transcorre da preocupação dos mesmos em utilizar os recursos naturais de forma a respeitar os mecanismos de sustentação do ecossistema, para garantir a utilização do meio ambiente da propriedade por longas gerações através do manejo correto (SERAMIM, 2015).

Na recuperação da cobertura vegetal das APPs já degradadas, devem-se distinguir as orientações quanto ao tipo de afloramento de água, ou seja, sem ou com acúmulo de água inicial, pois o encharcamento do solo ou a submersão temporária nas chuvas, do sistema radicular dos indivíduos plantados, a profundidade do perfil e a fertilidade do solo são alguns dos fatores que devem ser considerados, pois são seletivos para as espécies que vão conseguir se desenvolver (RODRIGUES et al., 2000). 


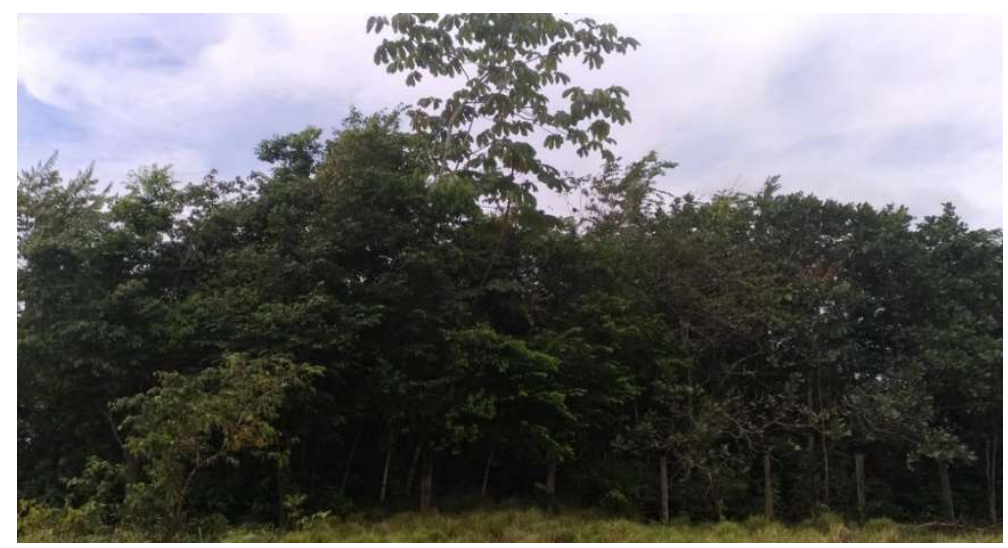

Figura 7: Imagem de área de 7 anos de recuperação.

As andirobeiras foram à primeira espécie a ser identificada na propriedade, devido a isso hoje são produzidas as primeiras mudas que são utilizadas dentro da mesma e consegue-se extrair óleo que é utilizado de forma medicinal para combater inflamações, quanto em pouquíssimas vezes comercializado com vizinhos para o mesmo fim. Não existe uma frequência na retirada do óleo devido os frutos serem direcionados pela família para a produção de mudas a fim de serem espalhados pela propriedade em si.

No entanto ao decorrer destes 23 anos, tem uma área de 1,57 ha recuperados com várias espécies florestais estabelecidos, que na qual podemos presenciar os galhos as folhas das árvores e alguns cipós. Portanto o dossel das plantas encontrasse bem desenvolvido e algumas outras plantas esperando a oportunidade da abertura do dossel para fazer a fotossíntese e poder se desenvolver.

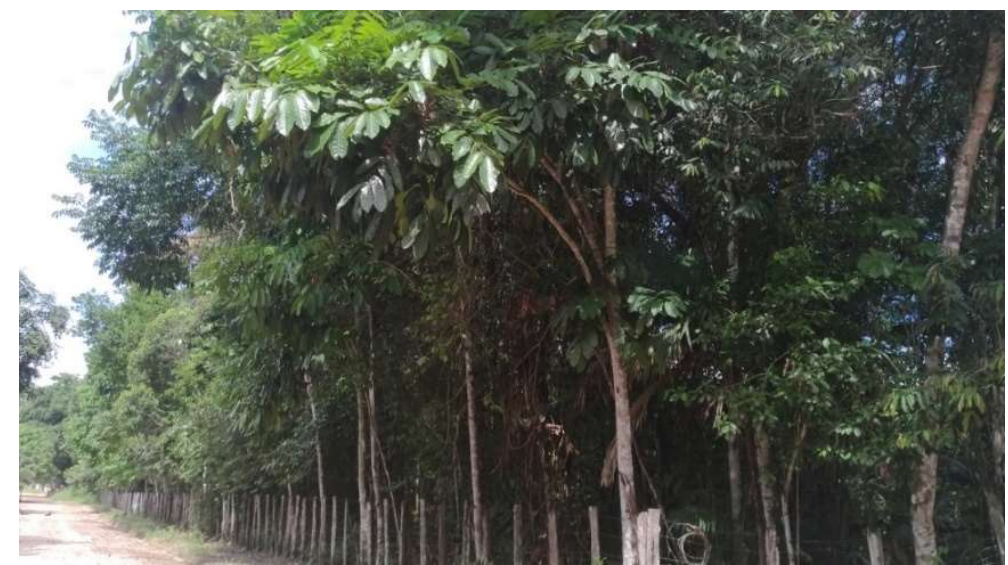

Figura 8: Imagem da área de 23 anos de recuperação.

Como discutido, a família tem uma pequena produção de frutos, animais e óleo. Porém, sabe-se que nas épocas de frutificação e produção divergem para cada espécie. Dificultando o lucro da família, pois não conseguem o valor desejado, porém a vantagem é que, devido essa produção de animais e frutos durarem o ano todo devido os diferentes ciclos a família consegue manter comercializando seus produtos e adquirindo renda para a própria manutenção da propriedade rural durante todo o ano.

Silva (2013), afirma que pensar estrategicamente, significa planejar e tomar qualquer decisão pensando em longo prazo, ou seja, o produtor rural não se baseia somente em culturas de ciclo curto mais sim em formas organizadas e diversificadas de produção, onde possam obter solos ricos e férteis e onde possam produzir continuamente. Essa estratégia de diversificar culturas e espécies nas propriedades rurais 
fortalece a economia das famílias e ajuda a garantir recurso em épocas onde há menor produção de frutos.

\section{Alternativas Adotadas}

Uma das alternativas que pode ser criada na propriedade devido ela ter uma grande área recuperada, é um bosque de interação, na qual a sua funcionalidade é de servir como corredor ecológico para as espécies, local de descanso para as pessoas que passam o estresse no meio urbano, interação das pessoas com o meio ambiente, principalmente crianças que são as futuras gerações, para que elas conheçam e convivam com espécies florestais e animais e tenham essa interação com o meio ambiente. Esse conhecimento é de extrema importância para que as pessoas tenham acesso ao espaço, noção de como é bom preservar para as futuras gerações principalmente seus filhos, e que busquem socializar suas informações adquiridas em uma simples caminhada.

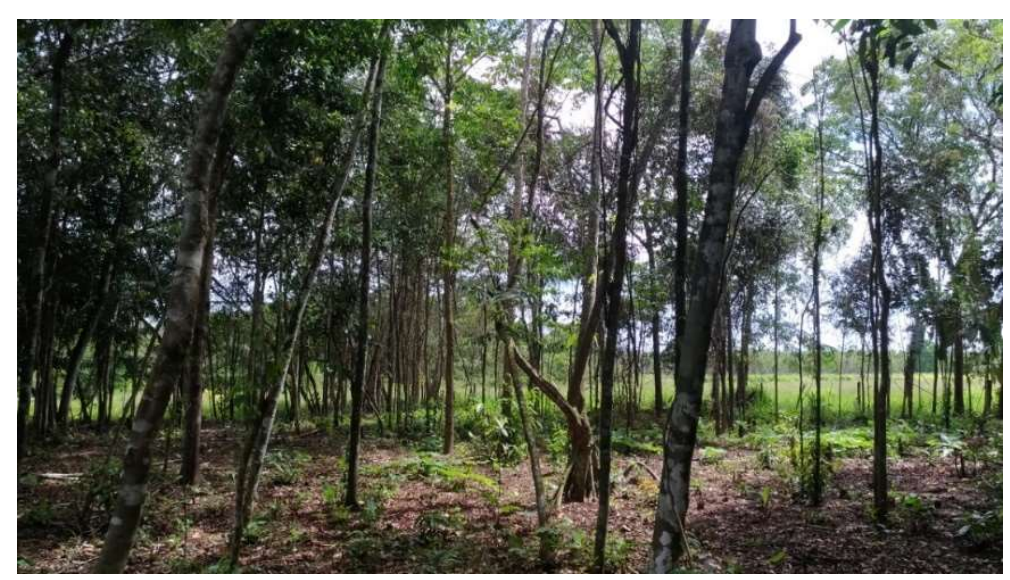

Figura 9: Imagem do Bosque de Interações as espécies florestais.

Os corredores ecológicos são de extrema importância para os animais, mostra a continuação da flora estabelecida, onde os animais que não eram mais presentes devido à derrubada das matas, voltam a se estabelecer em um espaço recuperado com diferentes espécies, portanto os pássaros e os animais, são responsáveis de espalhar as sementes quebrar a dormência, pois eles são um dos principais agentes dispersores de sementes.

Devido à grande lixiviação que acometia as nascentes do córrego foram implantadas algumas barreiras no solo com garrafas pet e pneus usados, formando um cordão que diminuiu a força da água das chuvas e minimiza a lavagem do solo e o assoreamento das nascentes, que por sua vez foi represada para aumentar o volume de água, outra forma de amenizar os impactos das chuvas no leito do córrego foi à implantação de algumas culturas como o açaí, banana e jaqueira.

$\mathrm{Na}$ área de entorno do córrego foi toda utilizada como APP (área de preservação permanente), para tentar ajudar na recuperação do meio ambiente e futuramente minimizar os impactos sofridos por ações de insolação, ventos e chuvas; as áreas mais afastadas foram divididas em campos de plantio e pastagens. Onde, nas áreas de plantio foram inseridas culturas como ingá, açaí, pupunha, abacaxi, maracujá, cupuaçu, limão, manga, laranja, tangerina, abóbora, acerola e banana. Sendo que, em toda a área tem a presença dos ingazeiros que produzem bastante biomassa e que auxilia na fixação de nitrogênio por ser uma leguminosa. No entorno e no meio da área preservada existem algumas espécies de ipê amarelo, mogno, acapu, andiroba, 
jarana, sapucaia e angelim pedra.

\section{CONCLUSÕES}

A transformação de floresta para agricultura ou pecuária tem contribuído para aumento do processo de erosão e assoreamentos de rios e igarapés, levando o mesmo a degradação do solo, na extinção de espécies da flora, fauna e nas mudanças climáticas. A utilização de mecanismos de proteção e recuperação de ambiente degradado, como reflorestar com espécies florestais nativas e agronômicas, favorecem uma melhor utilização do solo, o aumento de alimentos e a melhoria da qualidade de vida através dos serviços ambientais, tais como: sequestro de carbono, controle dos ventos, sombreamento, purificação da água e do retorno da fauna.

Nesse período de trabalho desenvolvido na propriedade, procurou-se observar os mecanismos da sucessão natural, porém, o retorno ecológico necessita de um período maior de tempo. Outro aspecto a ser observado é a formação de uma floresta com presença de um banco de plântulas e de sementes, que possam servir como fonte de propágulos para a área a ser recuperada.

Pode-se afirmar que as práticas sustentáveis quando aplicadas na agricultura familiar fomentam em qualidade de vida, tais práticas permitem que saiam de um possível quadro de instabilidade econômica e ambiental para algo mais sólido e seguro, capaz de auxiliar e garantir tanto para si quanto para gerações futuras qualidade de vida e solos com capacidade de produção que perduram sem precisar agredir o meio ambiente, e garantindo a sua subsistência de forma sustentável devido a diversidade de recursos que conseguiram criar nesse processo de transformação do ambiente.

Com poucos anos de recuperação da floresta, podemos considerar satisfatório, pois ela traz benefícios diretos e indiretos, o sequestro de carbono ocasionado pelas plantas, a fixação de nitrogênio feito por algumas leguminosas, proteção do solo contra a chuva e a insolação evitando que não aconteça algum tipo de erosão, observar a flora estabelecida, os animais que não haviam antes, a temperatura que antes era abafado devido não ter nem um tipo de proteção florestal, o sol castigava muito os produtores, no entanto tudo isso passou e hoje o que podemos perceber é a alegria do agricultor em poder está na sua propriedade preservada para suas futuras gerações.

\section{REFERÊNCIAS}

ALVES, M. C.. Recuperação do subsolo de um Latossolo Vermelho usado para terrapleno e fundação da usina hidrelétrica de llha Solteira. Tese (Doutorado) Universidade Estadual Paulista, Ilha Solteira, 2001.

ALVES, C. S. D.. Formas espaciais recentes da urbanização na Amazônia: a dinâmica sócio espacial do município de Castanhal em face do processo de dispersão metropolitana de Belém. Dissertação (Mestrado em Geografia) Universidade Federal do Pará, Belém, 2012.

AMARAL, M. D. B.; RIBEIRO, W. O.. Castanhal (PA): entre a dinâmica metropolitana e a centralidade sub-regional de uma cidade média. PRACS: Revista Eletrônica de
Humanidades do Curso de Ciências Sociais da UNIFAP, Macapá, v.9, n.1, p.77-105, 2016.

BARBOSA, L. M.. Manual sobre Princípios de Recuperação de Áreas Degradadas. São Paulo: SMA, 2000.

BENDAHAN, A. B.; VEIGA, J. B.. Avaliação das pastagens em propriedades leiteiras da microrregião de castanhal, estado do Pará. In: REUNIÃO ANUAL DA SBZ, 37. Anais. Viçosa, 2000. p.3.

EMBRAPA. Centro Nacional de Pesquisa de Solos. Sistema brasileiro de classificação de solos: 5 a aproximação. Rio de 
Janeiro: Embrapa Solos; Brasília: Embrapa Produção da Informação, 1999.

IBGE. Instituto Brasileiro de Geografia e Estatística. Diretoria de Pesquisas, Coordenação de População e Indicadores Sociais, Estimativas da população residente com data de referência 10 de julho de 2017. Rio de Janeiro: IBGE, 2010.

KAGEYMA, P. Y.; GANDARA, F. B.; OLIVEIRA, R. E.. Biodiversidade e restauração da floresta tropical. In: KAGEYAMA, P. Y.; OLIVEIRA, R. E.; MORAES, L. F. D.; ENGEL, V. L.; GANDARA, F. B.. Restauração ecológica de ecossistemas naturais. Botucatu: FEPAF, 2003. p.27-48.

MATA, M. F.. Biometria e morfologia de frutos e sementes de Inga striata Benth e I. ingoides (Rich.) Willd. In: REUNIÃO NORDESTINA DE BOTÂNICA, 29. Anais. Mossoró, 2006.

MENDONÇA, A. P.; FERRAZ, I. D. K.. Óleo de andiroba: processo tradicional da extração, uso e aspectos sociais no estado do Amazonas, Brasil. Revista Acta Amazônica, v.37, n.3, p.353-364, 2007.

MIRANDA, R. R.. Interfaces do rural e do urbano em área de colonização antiga na Amazônia: estudo de colônias agrícolas em Igarapé-Açu e Castanhal (PA). Revista de Geografia Agrária, v.7, n.14, p.1-36, 2012.

\section{PRODANOV, C. C.. Metodologia do trabalho científico:} métodos e técnicas da pesquisa e do trabalho acadêmico. 2 ed. Novo Hamburgo: Feevale, 2013.

RIBASKI, J.; MONTOYA, L. J.; RODIGHERI, H. R.. Sistemas Agroflorestais: aspectos ambientais e socioeconômicos. Informe Agropecuário, Belo Horizonte, v.22, n.212, p.61-67, 2001.
RODRIGUES, R. R.; SHEPHERD, G.. Fatores condicionantes da vegetação ciliar. In: RODRIGUES, R. R.; LEITÃO FILHO, H. F. Matas ciliares: conservação e recuperação. São Paulo: USP, 2000. p.101-107.

SANTOS, J. S.; SILVA TANAKA, L. M.; COSTA, G. B.. Um estudo da precipitação pluviométrica no município de Castanhal-PA. In: CONGRESSO BRASILEIRO DE METEOROLOGIA, 14. Anais Florianópolis, 2006.

SERAMIM, R. J.; LEISMANN, E. L.. A sustentabilidade na perspectiva da pequena propriedade rural: impactos com a adoção do Cadastro Ambiental Rural - CAR. In: CINGENCONFERÊNCIA INTERNACIONAL EM GESTÃO DE NEGÓCIOS, 1. Anais. Cascavel: UNIOESTE, 2015. p.13.

SILVA, R. A. G.. Administração Rural: teoria e prática. 3 ed. Curitiba, 2013.

SOUZA FILHO, A. P. S.; e ALVES, S. M.. Potencial alelopático de plantas de acapu (Vouacapoua americana): efeitos sobre plantas daninhas de pastagens. Planta Daninha, Viçosa, v.18, n.3, p.435-441, 2000.

SUDAM. Superintendência do Desenvolvimento da Amazônia. Diagnóstico de recursos naturais da área: programa Guamá - Acará - Moju. I. Solos e aptidão agrícola das terras. Belém: SUDAM, 1988.

VALENTE, M. A.; SILVA, J. M. L.; RODRIGUES, T. E.; CARVALHO, E. J. M.; ROLIM, P. A. M.; SILVA, E. S.; PEREIRA, I. C. B.. Solos e Avaliação da Aptidão Agrícola das Terras do Município de Castanhal, Estado do Pará. EMBRAPA, 2001.

VELOSO, H. P.; GOES FILHO, L.. Fitografia brasileira: classificação fisionômica: ecologia da vegetação neotropical. Salvador: Projeto RADAMBRASIL, 1982.

A CBPC - Companhia Brasileira de Produção Científica (CNPJ: 11.221.422/0001-03) detém os direitos materiais desta publicação. Os direitos referem-se à publicação do trabalho em qualquer parte do mundo, incluindo os direitos às renovaç̃̃es, expansões e disseminações da contribuiç̃o, bem como outros direitos subsidiários. Todos os trabalhos publicados eletronicamente poderão posteriormente ser publicados em coletâneas impressas sob coordenação da Sustenere Publishing, da Companhia Brasileira de Produção Científica e seus parceiros autorizados. Os (as) autores (as) preservam os direitos autorais, mas não têm permissão para a publicação da contribuição em outro meio, impresso ou digital, em português ou em tradução. 